\title{
Secretions and structures of the head of Sagitta setosa (Chaetognatha)
}

\author{
Helga Kapp ${ }^{1}$ \& Juliane Mathey ${ }^{2}$ \\ ${ }^{1}$ Taxonomische Arbeitsgruppe der Biologischen Anstalt Helgoland, Universität Ham- \\ burg, Zoologisches Institut und Zoologisches Museum; Martin-Luther-King-Platz 3, \\ D-2000 Hamburg 13, FRG \\ ${ }^{2}$ Zoologisches Institut der Universität Bonn; Poppelsdorfer SchloB, D-5300 Bonn 1, FRG
}

\begin{abstract}
The different secretions of the mouth, the vestibular organs, and the vestibular pits of chaetognaths are shown on scanning electron micrographs of the head of Sagitta setosa. The secreting organs are described and the functions of the secretions are discussed. In addition, the secretion under the praeputium, a pit between the two rows of anterior teeth, and the surface structure of the teeth are described.
\end{abstract}

\section{INTRODUCTION}

The head armature of chaetognaths has recently become the subject of research and discussion again, because scanning electron microscopy reveals the very fine structures and organs that are difficult to observe under the light microscope.

In their paper on the structures of the head of Sagitta hexaptera, Thuesen \& Bieri (1987) presumed that the vestibular pits and vestibular organs produce sufficient secretion for food intake. We suppose, however, that the voluminous secretion we found covering the mouth on REM photos of $S$. setosa is secreted in the oesophagus. This secretion seems to be the major part of the head secretions. In addition, we enter into further details revealed by our REM micrographs: the secretion under the praeputium, a pit between the two rows of anterior teeth, and the surface structure of the teeth of $S$. setosa.

\section{MATERIAL AND METHODS}

The specimens of S. setosa; the heads of which we used for REM photography, originated from the northern Adriatic Sea. The samples were collected in April 1986, from a depth of $5-0 \mathrm{~m}$, using a plankton net of $0.8 \mathrm{~m}$ in diameter, mesh size $280 \mu \mathrm{m}$. The specimens with well developed, but not mature, gonads had a body length of 10-11 mm. They were fixed and preserved in Bouin's solution (Romeis, 1968), dehydrated in ethanol, transferred to acetone and finally critical-point dried. They were sputter-coated with gold and observed using a Leitz AMR 1000 A scanning electron microscope. 


\section{RESULTS}

\section{Secretions of the head armature}

The scanning electron micrograph of Figure 1 shows the ventral side of the head with all the structures of the head armature. The most striking feature is the light mass, which is preserved secretion, filling the mouth region. This substance is partly torn away in Figure 2 and allows a view of the mouth opening below. Remains of preserved secretion are present in the mouth slit in Figure 3. Not only the mouth region but also the vestibular

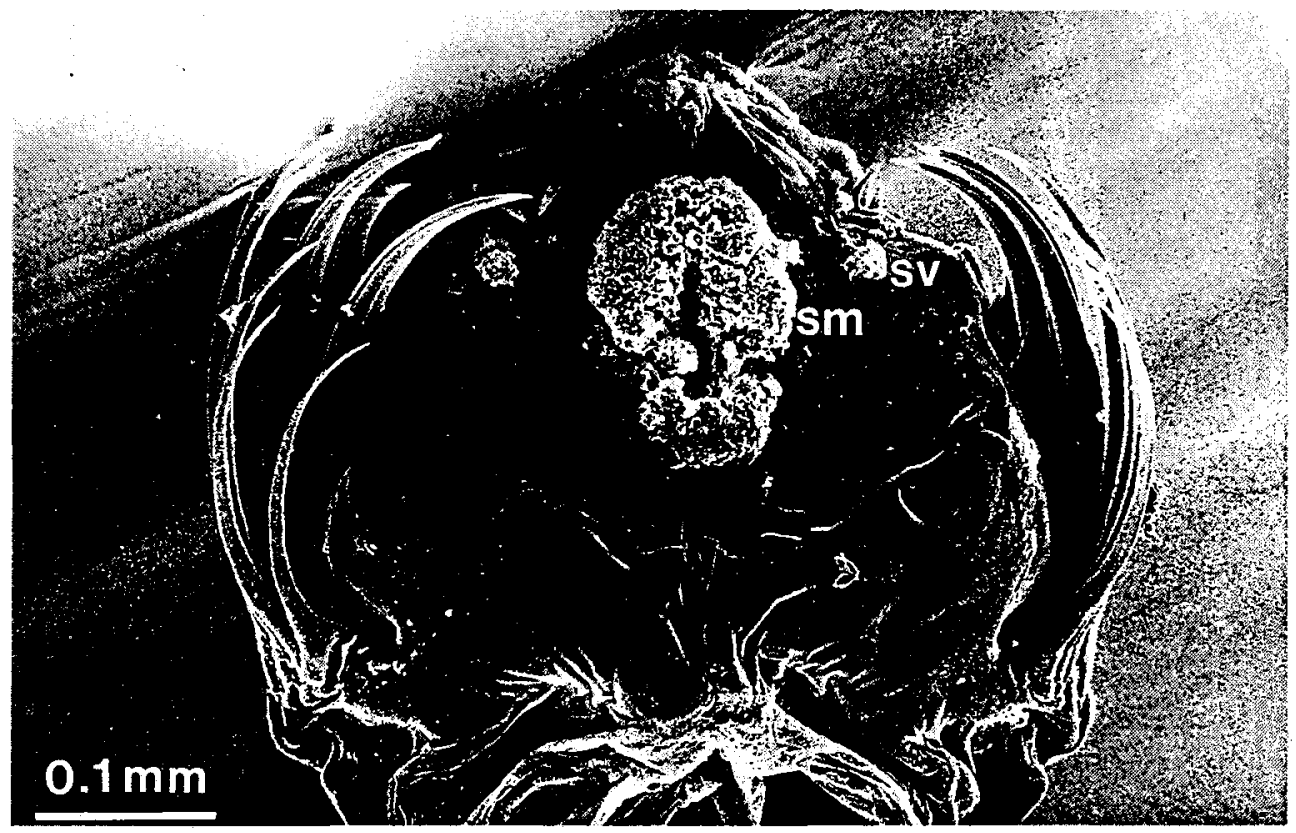

Fig. 1. Head of Sagitta setosa, ventral view, sm - secretion mass in the mouth region; sv - secretion covering the vestibular pits

pits are covered with secretion (Fig.1) which gives a rough impression of the relative quantities produced by the various organs.

The vestibular organs of $S$. setosa are ridges bearing a series of papillae with apical pores (Figs 2 and 3). They are situated just below the posterior teeth. The papillae are most pronounced laterally and become smaller mediad until the very last pores are no longer elevated. There are rests of secretion on or beside the vestibular pores. The papillae of the vestibular organs of $S$. setosa are multipored (Fig. 4) similar to those of S. hexaptera (Fig. 3, Thuesen \& Bieri, 1987). Evidently, a number of small tubes, i.e. excretory ducts, end at the tips of the vestibular papillae.

The large pores below the vestibular organs are the vestibular pits (Figs 2 and 3), covered with secretion in Figure 1 . Remains of secretion are visible either in the vestibular pits or partially overlapping them (Figs 2 and 3). The vestibular pits of $S$. setosa seem to correspond to those of $S$. hexaptera (Thuesen \& Bieri, 1987, Fig. 7). 


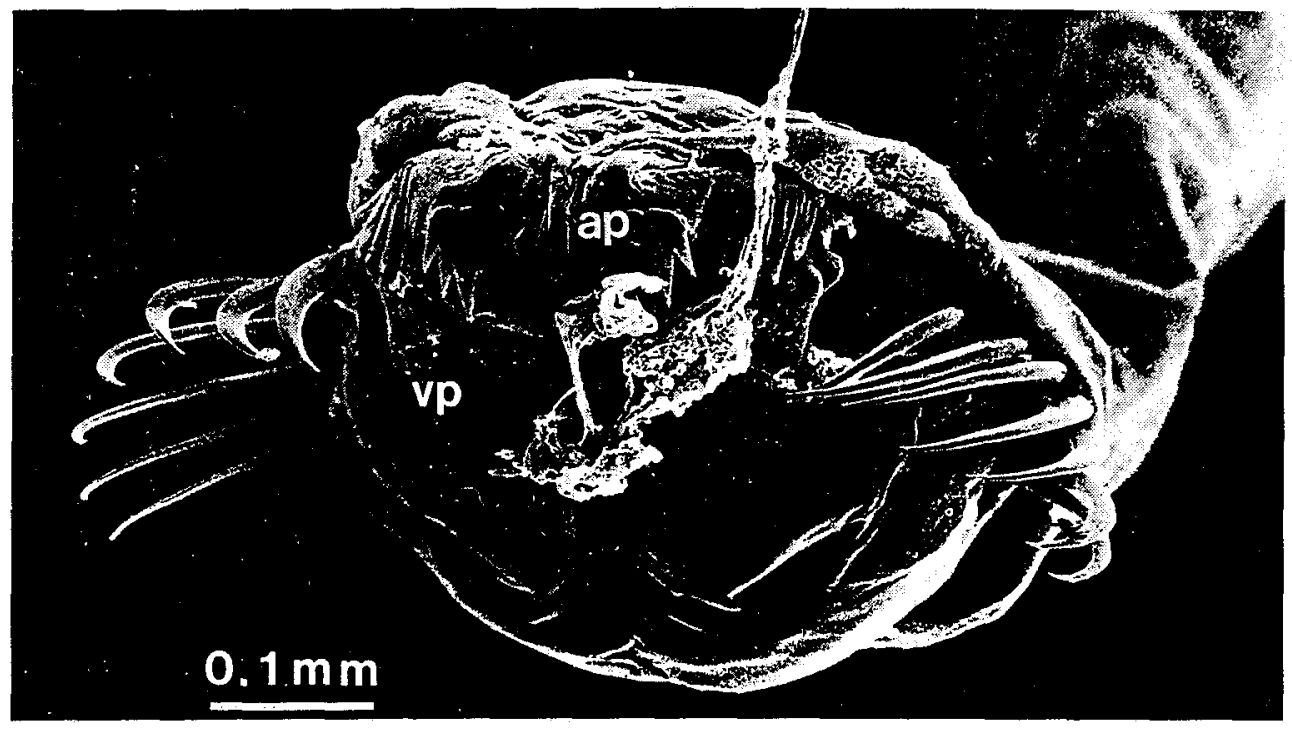

Fig. 2. Head of Sagitta setosa, anterior view, ap - apical pit ${ }_{i} v p-$ vestibular pit

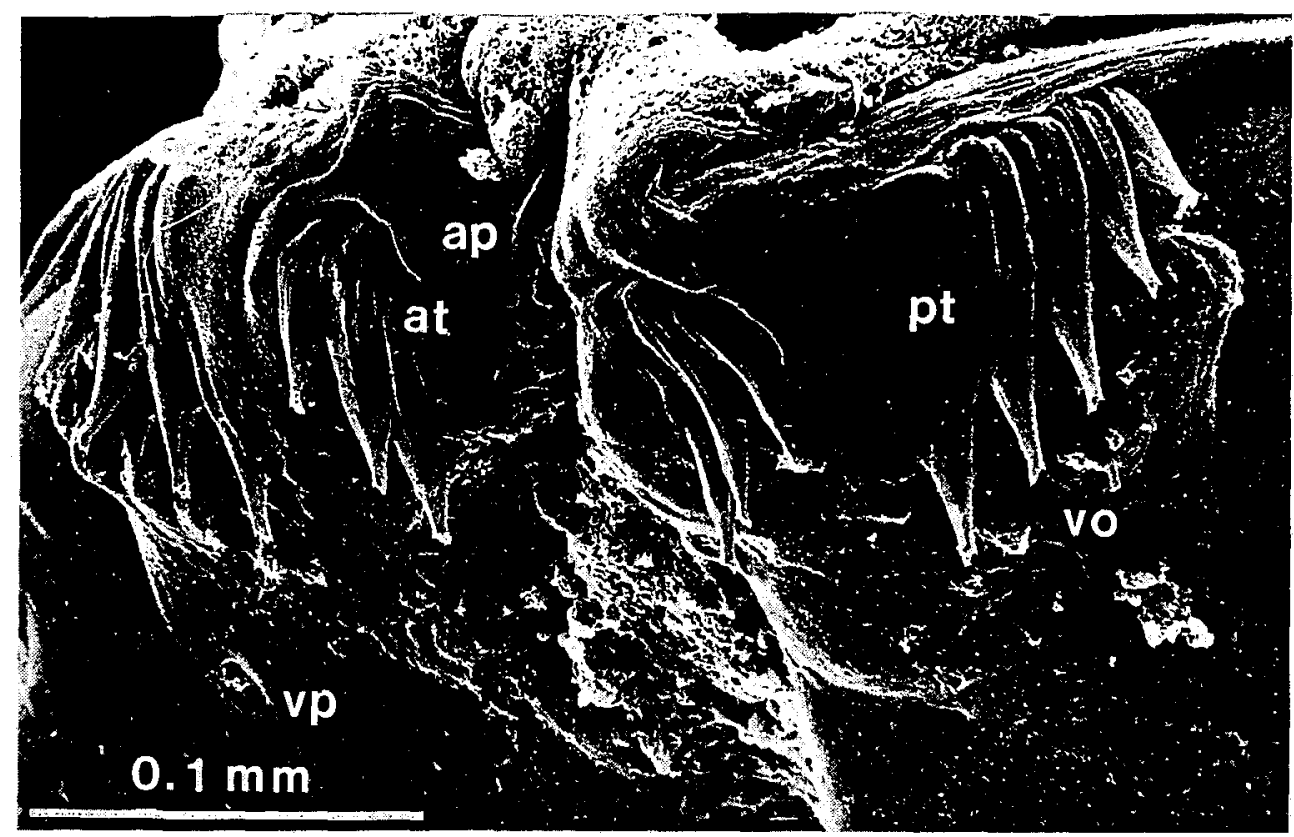

Fig. 3. Anterior part of the head of Sagitta setosa; ap - apical pit; at - anterior teeth; pt - posterior teeth; vo - vestibular organ; vp - vestibular pit 


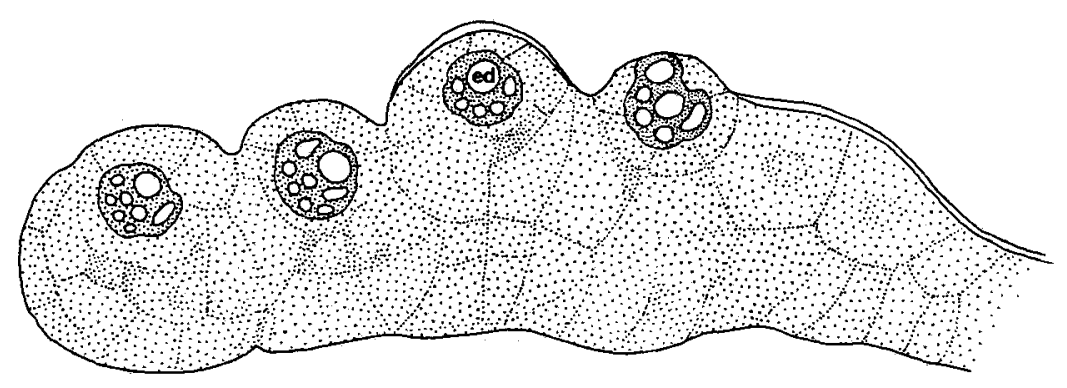

Fig. 4. Oblique section of the vestibular organ of Sagitta setosa; ed - excretory ducts

\section{Secretion under the praeputium}

Preserved secretions are also visible under the praeputium or hood (Fig. 2) and above the rows of teeth and lateral plates in Figure 3.

\section{Apical pit}

Not mentioned in the literature is a depression in the apical prominence bearing the anterior teeth (Figs 2 and 3). This depression separates the two rows of anterior teeth. In $S$ setosa it is formed like a pit into which a pulvinate tissue projects from the dorsal edge. It is narrower in Figure 3 , and the pulvinate tissue seems to be compressed into folds here.

\section{Teeth}

Figure 3 displaying the microstructure of the anterior and posterior teeth, complements the papers of Moreno (1979) and Furnestin (1977, 1982) on the teeth of many species, where an illustration of the teeth of S. setosa was missing. Furnestin (1982) only listed the teeth of $S$. setosa among the form group furnished with some carinae. Indeed, the surfaces of the anterior and posterior teeth are structured by two or three carinae. The points of the teeth seem to be broken and show sharp edges and spikes.

\section{DISCUSSION}

\section{Secretions of the head armature}

After catching their prey with hooks and teeth the chaetognaths coat and entangle it with a sticky secretion to prevent its escape and to avoid damage of their own buccal region and digestive tract. This sticky mucus functions not only as a protective layer but also has a paralysing effect (Parry, 1944; Bieri et al., 1983; Thuesen \& Bieri, 1987). The two latter authors presumed that this secretion is produced in the vestibular pits and that these organs are large enough to secret a sufficient quantity of mucus. In contrast, we suppose that the main part of secretion necessary for food intake is produced in the mouth region.

On the basis of the descriptions and drawings of Burfield (1927) and Parry (1944) and 
on our own observations, the oesophagus can be described as consisting of long cylindrical cells distally filled with granules of secretion; but the mouth slit which is lined by a monolayered epidermis lacks secreting cells. Furthermore, the epidermis surrounding the mouth does not contain glands. It is monolayered and covered with a thick cuticula like the whole ventral surface of the head. We agree with Parry (1944) that the secretion of the mouth is produced in the oesophagus.

The secretions of vestibular pits and organs must also be of importance for the food intake of chaetognaths, as Thuesen \& Bieri (1987) pointed out. Based on the fact that captured and relinquished copepods are unable to move, several authors (e.g. Feigenbaum \& Marris, 1984; Nagasawa, 1985) supposed toxic, paralysing substances are involved in the secretions of arrowworms. Recently, Thuesen et al. (1989) detected neurotoxin in head extracts of several species. An analysis of the secretions of the separate organs has not been carried out so far. (This will prove difficult since the vestibular organs and pits are tiny organs.) In the absence of such information, some uncertainties concerning the functions of the separate secretions still remain. Most probably, all the different secretions are important and play their own role in food intake. Presumably, they contain different substances including toxic ones. All these secretions operate together to enable a chaetognath to embody a prey organism, coated and paralysed by secretion. Presumably, the secretion of the mouth contains more sticky mucus, and the other secretions contain venoms.

\section{Secretion under the praeputium}

Feigenbaum \& Marris (1984, Fig.5) have already published a REM micrograph of $S$. friderici showing the secretions under the praeputium, but they did not mention these. These secretions are produced by the inner epidermis of the hood, which shows a well developed glandular epithelium (Ritter-Záhony, 1909; Kuhl, 1938), and probably by the broad secreting line that is present on the surface of the'head along the attachment of the hood (Ritter-Záhony, 1911). The function of these secretions is connected with the extremely rapid reactions of chaetognaths when capturing prey. The secretions produce a high slidability of the praeputium on the surface of the head, which is necessary as the grasping spines are spread out as fast as lightning and the hood must be retracted at the same high speed.

\section{Apical pit}

Extreme movements and form changes of the heads of chaetognaths are not unusual. The apical pit is considered as one feature enabling such extreme changes in form. Due to the different states of contraction of the head muscles (musculus expansus superior, m. e. inferior, m. obliquus capitis brevis), the apical depression varies in form appearing as a pit (Fig. 2) or as a slit (Fig.3; Fig. 14 in Bone et al., 1983). Different species show slightly different forms of apical pits (S. hispida: Cosper \& Reeve, 1970, Fig. 1; Bieri et al., 1983, Fig. 1; S. friderici: Feigenbaum \& Marris, 1984, Fig. 5). 


\section{Teeth}

On REM micrographs many tips of teeth appear with cusps; some cusps seem to be solid, but others seem to be the result of broken points. It is not sure whether these broken points are caused by preparation techniques or by natural processes. Bone et al. (1983) found out "that the tips of teeth and spines contain large amounts of silicon... Their silicon content renders them very hard..." Probably their very hardness does not always protect the tips from breaking. Bieri et al. (1983) and Thuesen \& Bieri (1987) presented the theory that the teeth pierce the exoskeleton of copepods in order to introduce the toxic secretions from the vestibular organs and vestibular pits. This could be achieved by the solid cusps at the tips of the teeth as well as by the sharp edges and spikes of the broken points. Nevertheless, an attempt should be made to find out the reasons for all the broken tips of teeth on REM micrographs.

Acknowledgements. We are grateful to Prof. G. Stein who enabled J. Mathey to work on chaetognaths. We thank K. Ulmen for her help in scanning electron microscopy and $\mathrm{E}$. V. Thuesen for generously sending his unpublished manuscript to us.

\section{LITERATURE CITED}

Bieri, R., Bonilla, D. \& Acros, F., 1983. Function of the teeth and vestibular ridge in the Chaetognatha as indicated by scanning electron microscope and other observations. - Proc. biol. Soc. Wash. 96 , 110-114.

Bone, Q., Ryan, K. P. \& Pulsford, A. L., 1983. The structure and composition of the teeth and grasping spines of chaetognaths. - J. mar. biol. Ass. U.K. 63, 929-939.

Burfield, S. T., 1927. Sagitta. - Proc. Trans. Liverpool biol. Soc. 41, 1-104.

Cosper, T. C. \& Reeve, M. R., 1970. Structural details of the mouth parts of a chaetognath species as revealed by scanning electron microscopy. - Bull. mar. Sci. 20, 441-445.

Feigenbaum, D. \& Marris, R. C., 1984. Feeding in the Chaetognatha. - Oceanogr. mar. Biol. 22, 342-392.

Furnestin, M.-L., 1977. Les dents de chaetognathes au microscope électronique à balayage. Relations avec la nutrition. - Rapp. P.-v. Réun. Commn int. Explor. scient. Mer Médit. 24, 141-142.

Furnestin, M.-L., 1982. Dents et organe vestibulaire des chaetognathes au microscope électronique à balayage. - Revue zool. afr. 96, 138-173.

Kuhl, W., 1938. Chaetognatha. - Bronn's Kl. Ordn. Tierreichs 4, Abt. 4, Buch 2, T.1, 1-226.

Moreno, I., 1979. Study of 'grasping spines and teeth of six chaetognath species observed by scanning electron microscopy. - Anat. Anz. 145, 453-463.

Nagasawa, S., 1985. The digestive efficiency of the chaetognath Sagitta crassa Tokioka, with observations on the feeding process. - J. exp. mar. Biol. Ecol. 87, 271-281.

Parry, D. A., 1944. Structure and function of the gut in Spadella cephaloptera and Sagitta setosa. J. mar. biol. Ass. U.K. 26, 16-36.

Ritter-Záhony, R. von, 1909. Chätognathen - Denkschr. Akad. Wissensch., Wien 84, Anhang 1-18.

Ritter-Záhony, R. von, 1911. Chaetognathi. - Tierreich 29, 1-35.

Romeis, B., 1968. Mikroskopische Technik. Leibniz Verl., München, 757 pp.

Thuesen, E. V. \& Bieri, R., 1987. Tooth structure and buccal pores in the chaetognath Flaccisagitta hexaptera and their relation to the capture of fish larvae and copepods. - Can. J. Zool. 65, $181-187$.

Thuesen, E. V., Kogure, K., Hashimoto, K. \& Nemoto, T., 1989. Poison arrowworms: a tetrodotoxin venom in the marine phylum Chaetognatha. - J. exp. mar. Biol. Ecol. 116, 249-2.56. 